\title{
COLECISTITIS AGUDA ALITIÁSICA
}

Revista Médica Sinergia Vol.3 Num:6

Junio 2018 pp: 3 - 8

(Acute alithiasic cholecystitis)

ISSN:2215-4523 EISSN:2215-5279 http://revistamedicasinergia.com

\section{DOI : https://doi.org/10.31434/rms.v3i6.128}

\section{RESUMEN}

La Colecistitis aguda alitiásica (CAA) o también llamada acalculosa, manifiesta la presencia de una inflamación de la vesícula biliar en ausencia de cálculos en su interior, es una entidad poco frecuente pero emergente y en muchas ocasiones secundaria a otras condiciones clínicas como; procesos infecciosos de estirpe viral o bacteriano, cirugía mayor, fármacos, traumatismos, ventilación mecánica, nutrición parenteral, quemaduras, entre otras.

Se caracteriza por presentar manifestaciones clínicas que no difieren en gran medida de las de la colecistitis litiásica, entre ellas; cuadro febril, ictericia, dolor localizado en el hipocondrio derecho, náuseas, vómitos y anorexia, signo de Murphy positivo o dudoso, hipersensibilidad del área y presencia de masa en cuadrante superior, correspondiente a esto, se debe considerar entre las posibilidades diagnósticas para todo paciente críticamente enfermo o herido con un cuadro clínico de sepsis o ictericia sin origen conocido, siendo la ecografía vesicular el estudio de gabinete de elección y permitiendo así instaurar el tratamiento médico, el cual incluye estabilización hemodinámica, supresión de fármacos capaces de dificultar el vaciado vesicular y la administración de antibióticos que tengan acción sobre aerobios gram negativos, enterococos y anaerobios, mientras que la colecistectomía de intervalo no está indicada después de un verdadero episodio de CAA y solo se reserva para pacientes con gangrena, perforación vesicular o cuando el drenaje percutáneo fracasa.

PALABRAS CLAVES: Colecistitis, alitiásica, acalculosa, vesícula, biliar.

\section{ABSTRACT}

Acute alithiasic aholecystitis or also called acalculous manifested by the presence of an inflammation of the gallbladder in the absence of stones inside, is a rare but emerging entity and in many cases secondary to other clinical conditions such as; infectious processes of viral or bacterial strain, major surgery, drugs, traumatisms, mechanical ventilation, parenteral nutrition, burns, among others. It is characterized by presenting clinical manifestations that do not differ greatly from those of lithiasic cholecystitis, among them; fever, jaundice, localized pain in the right hypochondrium, nausea, vomiting and anorexia, positive or doubtful Murphy sign, hypersensitivity of the area and presence of mass 
in upper quadrant, corresponding to this, should be considered among the diagnostic possibilities for every patient critically ill or injured with a clinical presentation of sepsis or jaundice with no known origin, with vesicular ultrasound being the study of choice and thus allowing the establishment of medical treatment, which includes hemodynamic stabilization, suppression of drugs capable of hindering vesicular emptying and the administration of antibiotics that act on gram negative aerobes, enterococci and anaerobes, while interval cholecystectomy is not indicated after a true episode of CAA and is reserved only for patients with gangrene, vesicular perforation or when percutaneous drainage fails.

KEY WORDS: Cholecystitis, alithiasic, acalculous, vesicle, biliary.

\section{INTRODUCCIÓN}

A través del tiempo se ha definido la colelitiasis como el estado de enfermedad más común que involucra a la vesícula biliar y al árbol biliar provocando colecistitis en numerosas ocasiones, sin embargo; a pesar de ser la más usual, existen otros tipos de colecistitis, entre las cuales destaca la colecistitis aguda alitiásica o también llamada acalculosa, la cual constituye en una entidad poco frecuente pero emergente $y$ en muchas ocasiones secundaria a otras condiciones clínicas, manifiesta la presencia de una inflamación de la vesícula biliar en ausencia de cálculos en su interior.

\section{EPIDEMIOLOGÍA}

La incidencia de la colecistitis aguda alitiásica (CAA) varía entre 2 y $15 \%$ en adultos según estudios consultados, en el caso de los niños puede llegar a representar del 30 al $50 \%$ del total de las colecistitis, pero sigue siendo de arduo diagnóstico ya que difícilmente se sospecha en edades tempranas. En el caso del género se presenta más en hombres que en mujeres siendo la relación de 1.5-3:1 y en edades superiores a la quinta década de la vida.

La mortalidad de la CAA depende de la condición médica subyacente, variando desde el $90 \%$ en pacientes críticamente enfermos, hasta el $10 \%$ en pacientes ambulatorios, pero siempre mayor que el $1 \%$ de mortalidad correspondiente a la colecistitis litiásica y además la enfermedad en sí misma puede empeorar rápidamente debido a la alta prevalencia de gangrena (aproximadamente 50\%) y perforación (aproximadamente 10\%).

\section{ETIOLOGÍA}

Las causas de la colecistitis acalculosa están relacionadas con infecciones de estirpe bacterial (anaerobios y gram negativos) por ejemplo Estreptococo Beta Hemolítico del grupo A, Salmonella y E.Coli o viral entre las que destacan: infección por Citomegalovirus, Virus de la Inmunodeficiencia Humana (VIH), Virus de Hepatitis A y B, Epstein Baar, 
Toxoplasmosis. Sin embargo, se ha comprobado una relación con el uso de nutrición parenteral prolongada, así como de quemaduras extensas, de traumatismos de tipo abdominal, de deshidratación y de cardiopatías con esta patología.

Los principales factores descritos como riesgo de CAA son cirugía mayor, uso de opioides y vasopresores, traumatismo, ventilación mecánica, deshidratación, quemaduras, shock, síndrome de respuesta inflamatoria sistémica (SIRS), transfusiones múltiples y ayuno prolongado.

\section{PATOGENIA}

Se han postulado cuantiosas teorías para explicar la patogénesis de esta enfermedad, asintiendo actualmente que se trata de origen multifactorial. A pesar de esto numerosos estudios recalcan a la estasis biliar como el principal factor detonador de la colecistitis aguda acalculosa, ya que el espesamiento de la bilis, con un aumento de la concentración de sales biliares, podría obstruir el cístico, y los componentes normales de la bilis, como la lisolecitina y ácidos biliares podrían lesionar la mucosa.

Esta posibilidad está sustentada clínicamente por la asociación de colecistitis agudas alitiásicas con ayuno, uso de narcóticos, deshidratación, ventilación mecánica, anestésicos, nutrición parenteral, causas que a su vez se asocian con estasis vesicular.

Otra propuesta ha sido la insuficiencia vascular de la vesícula por isquemia, la cual está clínicamente apoyada por la asociación con trauma, sepsis, procedimientos quirúrgicos, causas que pueden disminuir la perfusión durante períodos de hipotensión. La hipotensión, deshidratación o administración de fármacos vasoactivos, disminuye la perfusión tisular, mientras que la presión intraluminal aumenta por estasis biliar, lo que disminuye la presión de perfusión de la vesícula biliar.

De manera curiosa la enfermedad relacionada con cálculos biliares se asocia con dilatación arterial y llenado venoso extensivo, mientras que la CAA se asocia con oclusiones arteriales múltiples y llenado venoso mínimo a ausente. Admitiendo que la oclusión de los pequeños vasos, en períodos de hipoperfusión podría ser el elemento fundamental en la patogénesis de la colecistitis alitiásica.

Otra causa involucrada ha sido la presencia de necrosis tisular producto de infecciones, trauma o endotoxemia, en especial a través de la activación de cascadas inflamatorias. Las células de la vesícula biliar humana estimuladas in vitro con lipopolisacáridos secretan eicosanoides y factor activador de plaquetas, cuando se da una respuesta del huésped a la bacteriemia gramnegativa o a la lesión por isquemia, los mediadores vasoactivos juegan un papel muy importante en la patogénesis de CAA. En relación a la participación directa de gérmenes, los cultivos de bilis son negativos en la mitad de los casos, mientras que en otros se obtienen gérmenes variados, en particular Gram negativos y Candida albicans.

\section{CLÍNICA}

A diferencia de la colecistitis litiásica, que presenta un predominio en el sexo femenino, la colecistitis alitiásica es más frecuente en varones. Las manifestaciones clínicas no difieren demasiado de las de la colecistitis 
litiásica. En un $65 \%$ de los casos existe fiebre mayor de $38^{\circ} \mathrm{C}$, el dolor está presente en la mayoría de los casos, localizado en el hipocondrio derecho en un $70 \%$ y difuso en un $30 \%$ de los pacientes, pueden asociar distensión abdominal, ausencia o disminución de ruidos peristálticos, náuseas, vómitos y anorexia.

A la exploración física se puede encontrar signo de Murphy positivo o dudoso, hipersensibilidad del área y presencia de masa en cuadrante superior y en cerca de la mitad de los casos puede existir defensa involuntaria.

Los informes de colecistitis aguda como complicación posquirúrgica, tras traumatismo múltiple o lesión por quemaduras son numerosos y es tan probable que se desarrolle en presencia de cálculos biliares como en su ausencia. El desarrollo de CAA no se limita a pacientes quirúrgicos 0 heridos, la diabetes mellitus, la vasculitis abdominal, la insuficiencia cardíaca congestiva, la embolización de colesterol de la arteria cística, y la resucitación por shock hemorrágico o paro cardíaco se han asociado con episodios de colecistitis aguda alitiasica.

La colecistitis acalculosa también puede desarrollarse como una infección secundaria de la vesícula biliar durante la sepsis sistémica causada por candidiasis diseminada, o leptospirosis; o durante el curso de enfermedades diarreicas activas 0 con tuberculosis, malaria, brucelosis, fiebre $Q$ y dengue.

La obstrucción biliar extrahepática puede provocar CAA por causas infecciosas como ascariasis y por causas no infecciosas como hemobilia, quiste de colédoco, y estenosis ampular.

\section{DIAGNÓSTICO}

Actualmente la frecuencia de la colecistitis aguda alitiasica ha incrementado lo suficiente como para que se deba considerar entre las posibilidades diagnósticas en todo paciente críticamente enfermo o herido con un cuadro clínico de sepsis o ictericia sin origen conocido.

El diagnóstico rápido y preciso es esencial, ya que la isquemia de la vesícula biliar puede progresar rápidamente a gangrena, empiema 0 perforación. Los estudios de laboratorio no son concluyentes en todos los pacientes, sin embargo, los más recomendados ya que presentan alteraciones son: hemograma con presencia de leucocitosis, elevación de proteína C reactiva (PCR) y de velocidad de sedimentación globular (VSG), aumento de bilirrubinas, transaminasas, fosfatasa alcalina y amilasa.

La ecografía vesicular es el estudio de gabinete de elección, con una sensibilidad del $85 \%$ y especificidad del $95 \%$, se deben cumplir dos criterios mayores o un criterio mayor y dos menores para establecer el diagnóstico.

Los criterios mayores:

- Espesor de la pared de vesícular mayor o igual a $3.5 \mathrm{~mm}$

- Líquido pericolecistico o edema subseroso

- Distensión mayor de $5 \mathrm{~cm}$ de largo

- Gas intramural o colecistitis enfisematosa

Los criterios menores:

- Lodo biliar e hidrops 
- Distensión mayor o igual a $8 \mathrm{~cm}$ o mayor de $5 \mathrm{~cm}$ de ancho con líquido transparente

La tomografía computarizada parece ser tan precisa como la ecografía en el diagnóstico de CAA, los criterios diagnósticos son similares a los descritos para la ecografía. Se han notificado exploraciones con ultrasonidos falsos positivos, y pueden ocurrir en particular cuando las afecciones incluyen lodo, cálculos no oclusivos, colesterolosis, hipoalbuminemia o ascitis imitan una pared engrosada de la vesícula biliar.

\section{TRATAMIENTO}

Se puede prevenir el desarrollo de colecistitis alitiásica por medio de la administración periódica de alimentos grasos o la administración intravenosa de colecistoquinina en pacientes de alto riesgo los cuales se encuentran en unidades de cuidados intensivos.

Los pacientes de reconocimiento temprano pueden ser sometidos a tratamiento médico exclusivamente, el cual incluye una correcta estabilización hemodinámica, la supresión de fármacos capaces de dificultar el vaciado vesicular y la adecuada administración de antibióticos que tengan acción sobre aerobios gram negativos, enterococo y anaerobios.

El drenaje percutáneo transhepático tiene la ventaja de que puede realizarse con anestesia local y en la cama del paciente, pero puede ser insuficiente en casos de gangrena vesicular 0 perforación.

La permeabilidad del conducto cístico puede determinarse inmediatamente mediante colangiografía, la cual debe debe realizarse después de que el paciente se haya recuperado para determinar la presencia de cálculos biliares no detectados inicialmente. Si hay cálculos biliares, generalmente se recomienda una colecistectomía electiva. La colecistectomía de intervalo generalmente no está indicada después de un verdadero episodio de CAA y actualmente queda reservada para pacientes con gangrena, perforación vesicular o cuando el drenaje percutáneo fracasa.

\section{COMPLICACIONES}

La colecistitis enfisematosa es una de las complicaciones de la CAA, más del $70 \%$ de los casos ocurre en hombres, y el $20 \%$ de los pacientes tiene diabetes mellitus, la presencia de crepitación en la palpación o la identificación radiográfica del gas en pacientes con colecistitis aguda exige una colecistectomía inmediata.

La perforación de la vesícula biliar ocurre en cerca del $10 \%$ de los casos sino es que en más, ya sea localizado en el duodeno adyacente 0 en el colon transverso originando una fístula colecistoentérica; 0 en el espacio subhepático, que causa la formación de abscesos; o perforación libre con peritonitis generalizada.

La perforación en el hígado o del el tracto biliar se ha notificado raramente en la colecistitis aguda alitiasica, así como la perforación retroperitoneal.

La causa habitual de muerte inmediata en esta patología es la sepsis con síndrome de disfunción orgánica múltiple, mientras que las causas inusuales de muerte en CAA incluyen hemorragia del hígado y embolia biliar pulmonar. 
Las complicaciones graves de la gangrena de la vesícula biliar sin perforación incluyen pancreatitis aguda, perforación del colon y obstrucción del conducto hepático común. La embolia de la vesícula biliar también puede complicar la CAA.

\section{BIBLIOGRAFÍA}

1. Rosas-González G, Carreño-Vásquez K \& Ramírez-Onofrea C. (2017). Colecistitis Aguda Alitiásica: A Propósito de un Caso en Paciente Adolescente. Salud y Administración, 4, 53-57.

2. De Oliveira JSA et al. (2016). Acute acalculous cholecystitis in critically ill patients risk factors diagnosis and treatment strategies. Journal of Pancreas, 17, 580-586.

3. Blasco AJ et al. (2014). Colecistitis aguda alitiásica en Pediatría. Una patología no tan rara. Revista Española de Enfermedades Digestivas, 106, 487-490.

4. Papadakis A. (2014) Colecistitis aguda. Papadakis A. Diagnóstico Clínico y Tratamiento. 52 ed. México: Mc Graw Hill Interamericana, 704-705.

5. Granados R \& Jiménez E. (2013). Colecistitis Acalculosa en el Paciente Quemado. Rev Cl Emed Ucr, 3, 11-15.

6. Motta RGA \& Rodríguez TC. (2010). Abordaje diagnóstico por imagen en patología benigna de la vesícula y vía biliar. Asociación Mexicana de Cirugía Endoscópica, 11,719.

7. Philip S. Barie \& Soumitra R. (2010). Acute Acalculous Cholecystitis, Gastroenterology Clinics of North America, 39, 343-357.

Recepción: 13 Marzo de 2018

Aprobación: 20 Mayo de 2018 